\title{
A very rare case of a newborn with tetrasomy $9 p$ and literature review
}

\author{
Merve Süleyman ${ }^{\oplus}$, Sümeyra Oğuz ${ }^{2 \odot}$, Gözdem Kayki ${ }^{3 \oplus}$ Hasan Tolga Çelik ${ }^{3 \odot}$, \\ Pelin Özlem Şimsek Kiper ${ }^{4 \oplus}$, Gülen Eda Utine ${ }^{4 \oplus}$, Şule Yiğit ${ }^{3 \oplus}$ \\ Departments of ${ }^{1}$ Pediatrics, ${ }^{2}$ Medical Genetics, ${ }^{3}$ Neonatology, and ${ }^{4}$ Pediatric Genetics, Hacettepe University Faculty of Medicine, \\ Ankara, Turkey.
}

\begin{abstract}
Background. Tetrasomy $9 \mathrm{p}$ is a rare genetic condition which usually results from a supernumerary isochromosome derived from the short arm of chromosome 9. Phenotypic findings include multiple congenital anomalies, facial dysmorphism, growth and developmental delays, and also vary according to the presence and degree of mosaicism.

Case. We report on a newborn with tetrasomy $9 \mathrm{p}$ who deceased in the newborn period. She had facial features including low-set and anteverted ears, hypertelorism, prominent nasal bridge, and microretrognathia. Bilateral ventriculomegaly, vermian hypoplasia and corpus callosum agenesis were detected on magnetic resonance imaging and double outlet right ventricle (tetralogy of Fallot type), secundum atrial septal defect, and persistent left superior vena cava were displayed by echocardiography. Microarray analysis revealed 38,584 kb tetrasomic region at 9p24.3p13.1. We also present a review of the literature suggesting that there is a recognizable phenotype for this condition and an assessment of cardiac manifestations based on the size and the localization of the breakpoints.

Conclusions. We conclude that cardiac manifestations do not differ according to the localization of the breakpoint. Persistent left superior vena cava seems to be consistent with breakpoints distal to q12, but the present case is different from them by breakpoint p13.1.
\end{abstract}

Key words: tetrasomy 9p, isochromosome, mosaicism, tetralogy of Fallot, cardiac manifestations.

Tetrasomy $9 \mathrm{p}$ is a rare genetic condition which usually results from a supernumerary isochromosome derived from the short arm of chromosome 9 and also demonstrates cytogenetic and phenotypic variability.

Phenotypic features include multiple congenital anomalies, facial dysmorphism, growth and developmental delay. Most common dysmorphic traits are hypertelorism, low-set abnormal ears, bulbous nose and microretrognathia. Intrauterine growth restriction (IUGR), Dandy-Walker malformation, cleft lip and/or palate, congenital

$\triangle$ Merve Süleyman mrv.ystl@gmail.com

Received 19th March 2021, accepted 30th March 2021. heart defects, joint dislocations, hypoplasia of the digits and nails have also been reported. ${ }^{1}$

About $30 \%$ of the tetrasomy $9 p$ cases are in mosaic state. ${ }^{2}$ Although mosaic cases may be phenotypically normal or mildly affected, most cases in non-mosaic constitution are lethal in the early postnatal period due to severe malformations., ${ }^{3,4}$ Herein, we report on a newborn with tetrasomy $9 p$ who died at postnatal 22nd day due to severe cardiovascular collapse.

\section{Case Report}

A full-term female infant was born from the third pregnancy of the 44-year-old mother as the first liveborn child. At birth, the child 
weighed $2320 \mathrm{~g}$, and her head circumference was measured at $33 \mathrm{~cm}$ (both values below the third percentile). First and fifth minute Apgar scores were 6 and 7, respectively. The parents were not consanguineous. Antenatally the second-trimester triple screen yielded a risk of higher than 1 in 50 for trisomy 18, and detailed fetal ultrasonography showed hydrocephalus and cardiomegaly. The parents refused amniocentesis. The family history was unremarkable except the two spontaneous miscarriages.

The newborn was transferred to our hospital on postnatal day 7 because of hypotonia. She was admitted to the neonatal intensive care unit and intubated because of increased work of breathing and placed on mechanical ventilator. On physical examination, anterior and posterior fontanel measurements were $3.5 \times 4 \mathrm{~cm}$ and $2 \times 2 \mathrm{~cm}$, respectively. Metopic suture was not ossified and was palpable. She had low-set and anteverted ears, hypertelorism, prominent nasal bridge, microretrognathia, $3 / 6$ systolic murmur, labial hypoplasia, and bilateral metatarsus adductus (Fig. 1). There were also bilateral single palmar creases, and besides, there were single digital flexor creases on bilateral fifth fingers and a second finger on the right.

Ophthalmological examination revealed no retinal or lenticular pathology. Cranial ultrasonography showed bilateral ventriculomegaly, vermian hypoplasia and corpus callosum agenesis. In addition, hypoplasia of brain stem was detected on cranial magnetic resonance imaging (Fig. 2). Echocardiography showed presence of double outlet right ventricle (tetralogy of Fallot type), secundum atrial septal defect, and persistent left superior vena cava. Abdominal ultrasonography revealed renal bilateral pelvic dilatation and abnormal superior mesenteric arteriovenous drainage. Hypoplasic first rib and costal scalloping was observed on X-rays (Fig. 2).

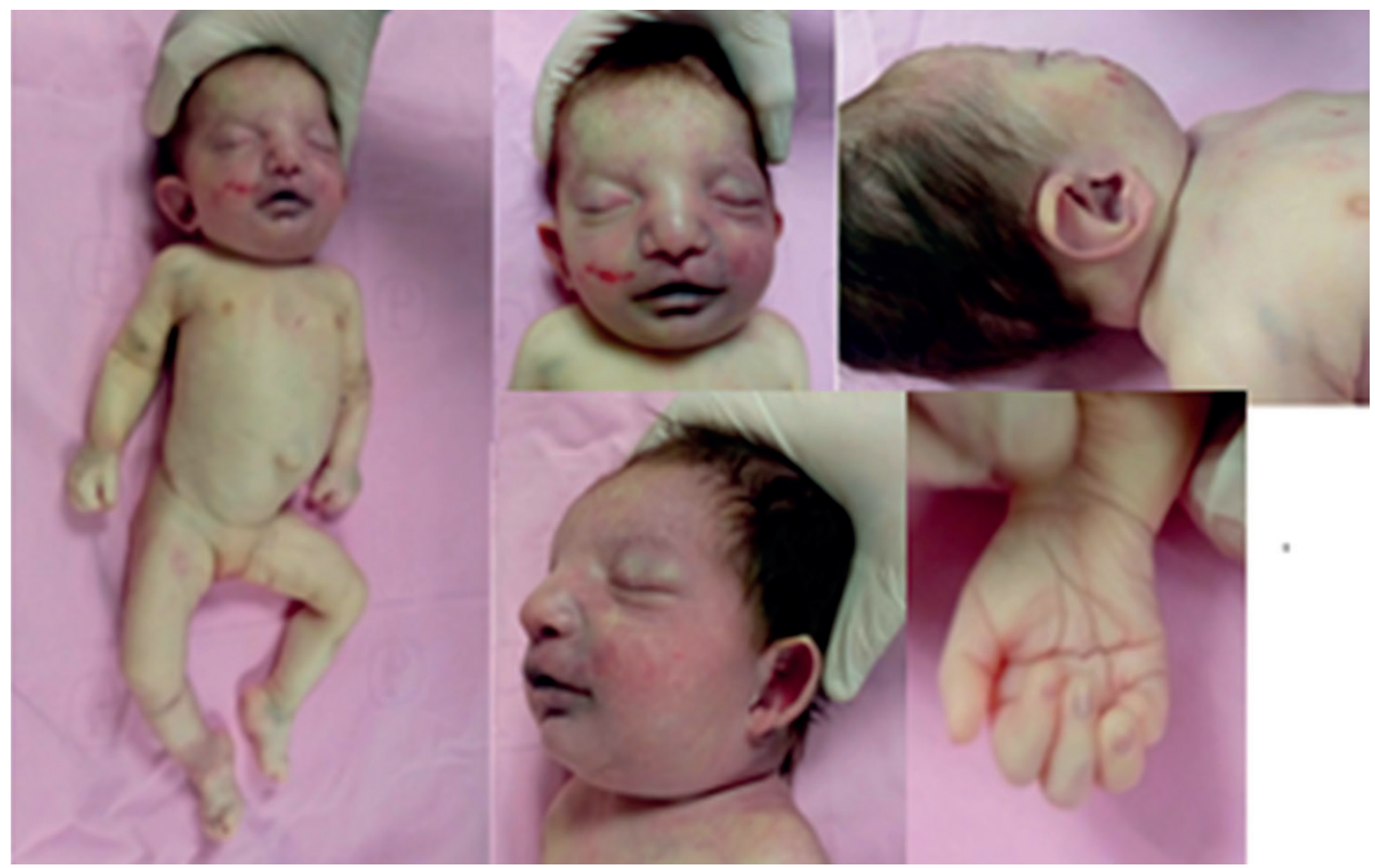

Fig. 1. Overall appearance and facial features of the patient. Hypertelorism, prominent nasal bridge, bulbous nose, low-set and poorly formed ears, microretrognathia, and single palmar crease were remarkable. 


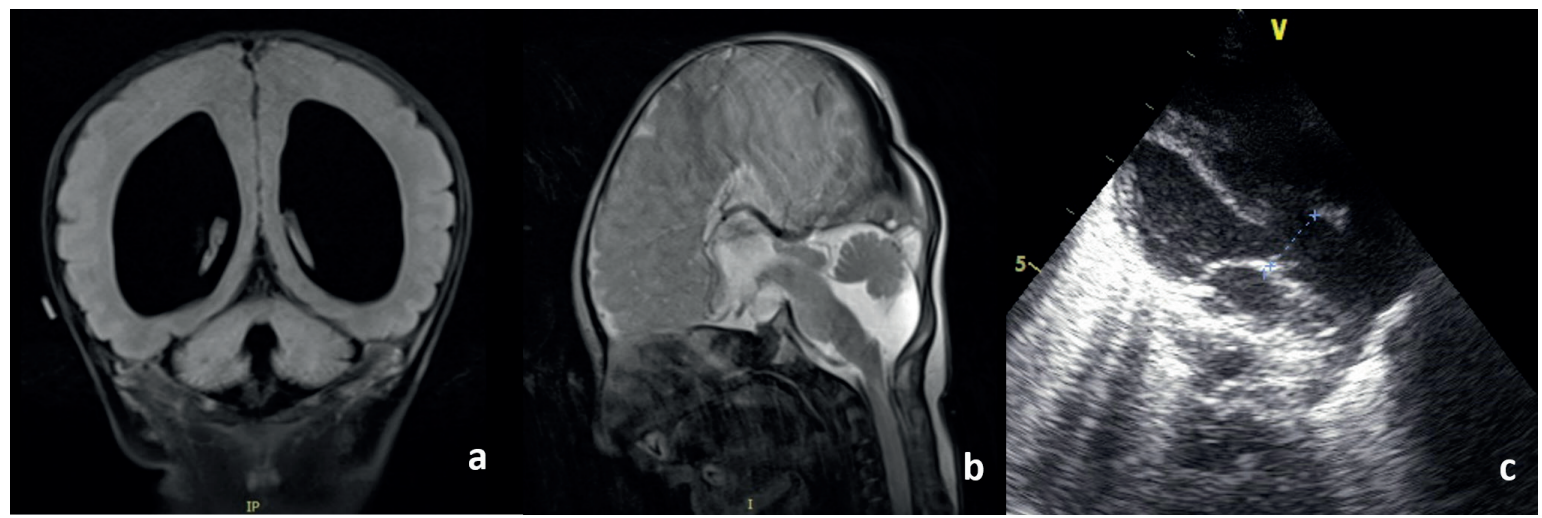

Fig. 2. (a) Magnetic resonance imaging revealed inferior vermian hypoplasia and ventriculomegaly. (b) Agenesis of corpus callosum. (c) Echocardiography displayed presence of double outlet right ventricle.

The baby was fed with an orogastric catheter and was supported parenterally. She received meropenem, vancomycin, amikacin and fluconazole for catheter-related thrombophlebitis and late neonatal sepsis. The newborn's general health condition deteriorated progressively and she died at the 22nd day due to severe cardiovascular collapse.

After informed consent was taken from the parents, peripheral blood was obtained to isolate genomic DNA using standardized protocols for salt precipitation. Microarray procedure was performed using the GeneChip ${ }^{\circledR}$ CytoScan Optima Array (Affymetrix, Santa Clara, USA) following the manufacturer's recommendations. Chromosome Analysis Suite (ChAS®) software (Affymetrix, Santa Clara, USA) was utilized for the analysis, using in-house data and public databases like Database of Genomic Variants (DGV) and Database of Chromosomal Imbalance and Phenotype in Humans using Ensemble Resources (DECIPHER). Microarray analysis revealed $38,584 \mathrm{~kb}$ tetrasomic region at 9p24.3p13.1, encompassing 492 genes and 165 OMIM genes (arr hg[19] 9p24.3p13.1 (203,861$38,787,480) \times 4)$.

Her family provided written informed consent for publication of this report and the accompanying images.

\section{Discussion}

Autosomal tetrasomies are rare genetic conditions most commonly caused by isochromosomes and very seldomly by intrachromosomal amplifications. ${ }^{5}$ The most commonly encountered isochromosomes are $i(8 p), i(9 p), i(12 p), i(18 p)$ and $i(22 q) .{ }^{1}$ The isochromosomes of the short arms of chromosomes 5, 10 and 20 have also been reported as individual cases. ${ }^{6-8} \mathrm{U}$-type exchange is the proposed underlying mechanism for the formation of isochromosomes. ${ }^{9}$ Tetrasomy $9 p$ usually results from a supernumerary isochromosome derived from the short arm of chromosome 9. This isochromosome can be grouped into one of the three types: those that originate from $9 p$ alone, those that involve entire $9 p$ with additional heterochromatic band from $9 q$, or those that involve the entire $9 p$ with additional heterochromatic and euchromatic bands from $9 \mathrm{q} \cdot{ }^{10,11}$

Tetrasomy 9p was first reported in 1973 by Ghymers and 72 cases have been reported since then. ${ }^{1,2,7-9,12-15}$ Clinical manifestations of the disease include psychomotor retardation (\%73), ear deformity (69\%), skeletal anomalies (57\%), hypertelorism (56\%), microretrognathia (46\%), urogenital-renal anomalies (43\%), eye anomalies $(43 \%)$, bulbous nose $(40 \%)$, congenital heart 
disease $(40 \%)$, cleft lip and/or palate $(33 \%)$, clino-camptodactyly (26\%), down slanting lips (24\%) and microcephaly (20\%) (Table I). ${ }^{1,2,14,16-20}$ Although most isochromosomes are maternal in origin, no correlation between maternal age and this chromosomal pathology seems to exist. In the reported study the mean maternal age was found to be 33.9 years. The present patient had lots of these clinical findings and her maternal age was 44 years.

Sometimes, tissue-specific mosaicism for isochromosomes is observed; such as $\mathrm{i}(12 \mathrm{p})$ found in skin fibroblasts in Pallister-Killian syndrome or $\mathrm{i}(9 \mathrm{p})$ in lymphocytes with a lower level in fibroblasts. Mosaicism causes diagnostic difficulties, especially prenatally. ${ }^{13}$ It is recommended to study fetal blood samples with uncultured prenatal specimens, to prevent missed diagnosis, until noninvasive prenatal screening using cell-free fetal DNA from maternal blood presents data from all set of chromosomes, and becomes widely available. ${ }^{11-14}$

On the other hand, prenatal ultrasonographic findings are valuable for the morphological diagnosis, and most frequent findings in tetrasomy $9 p$ are ventriculomegaly, DandyWalker malformation, intrauterine growth retardation, genitourinary anomalies, and cleft lip and/or palate. ${ }^{15,19,21,22}$ The present patient had ventriculomegaly detected prenatally, consistent with these reports. Facial dysmorphic features were also consistent with the condition, such as open sutures, wide fontanels, hypertelorism, prominent nasal bridge and microretrognathia.

According to the already existing literature, $78 \%$ of patients have central nervous system malformations, with ventriculomegaly and Dandy-Walker malformation being the most frequently detected anomalies. ${ }^{1,2,16,19,21-33}$ The present patient had bilateral ventriculomegaly, vermian hypoplasia, corpus callosum agenesis and brain stem hypoplasia.

This condition is very rarely encountered, and affected individuals do not survive, particularly when in non-mosaic condition. Therefore, a clear delineation of the phenotype is difficult to establish. The degree of mosaicism and the size of the isochromosome expectedly contribute to the phenotype and survival rates. ${ }^{21}$ We consider that the condition in the present patient was non-mosaic, although no second tissue was sampled for karyotype analysis.

During the last 20 years, researchers have observed a wide variety of cardiac anomalies in tetrasomy $9 p$ patients. In the presented

Table I. Clinical findings of tetrasomy $9 \mathrm{p}$ and comparison of our patient's findings with them. ${ }^{1,2,14,16-20}$

\begin{tabular}{lccc}
\hline & Literature n:73 & Overall & The Present Patient \\
\hline Maternal age & $33.9(\mathrm{n}: 66)$ & 33.9 & 44 \\
Psychomotor retardation & $24 / 33$ & $73 \%$ & + \\
Low-set / malformed ears & $47 / 68$ & $69 \%$ & + \\
Skeletal anomalies & $38 / 67$ & $57 \%$ & + \\
Hypertelorism & $32 / 57$ & $56 \%$ & + \\
Micro/retrognathia & $31 / 68$ & $46 \%$ & + \\
Urogenital anomalies & $29 / 67$ & $43 \%$ & + \\
Ophthalmological anomalies & $23 / 54$ & $43 \%$ & + \\
Bulbous tip of nose & $27 / 67$ & $40 \%$ & + \\
Cardiac defects & $27 / 68$ & $40 \%$ & + \\
Cleft lip/ palate & $22 / 67$ & $33 \%$ & + \\
Clino- camptodactyly & $17 / 66$ & $26 \%$ & + \\
Down slanting lips & $16 / 66$ & $24 \%$ & + \\
Microcephaly & $13 / 66$ & $20 \%$ & + \\
\hline
\end{tabular}


case, echocardiography revealed pulmonary stenosis, double outlet right ventricle (tetralogy of Fallot type), secundum atrial septal defect and persistent left superior vena cava. Lloveras et $\mathrm{al}^{32}$ and Leichtman et al. ${ }^{34}$ previously reported atrial septal defect in tetrasomy $9 \mathrm{p}$ cases. Dhandha et al. ${ }^{21}$ published three patients with severe congenital heart disease. The malformations included ventricular septal defect, right ventricular outflow tract stenosis, hypoplastic left ventricle, aortic stenosis, thick tricuspid valve and also persistent left superior vena cava. All three patients had isochromosome $9 p$ with segmental euchromatic material from 9q. Cardiac findings have been reported mostly associated with isochromosomes involving $9 \mathrm{q}$ segments, but the patient presented here had major heart defects despite being tetrasomic only for segments from 9p. Persistent left superior vena cava (PLSVC) is a noteworthy cardiac finding in tetrasomy $9 p$ and previously reported cases have been associated with isochromosomes additionally involving $9 \mathrm{q}$ region. ${ }^{8}$ Infundibular stenosis of the right ventricular outflow tract and overriding aorta were reported previously, but to the best of our knowledge this is the first patient with double outlet right ventricle (tetralogy of Fallot type) with a tetrasomy $9 \mathrm{p} .{ }^{32}$

Cardiac manifestations of tetrasomy $9 p$ according to the breakpoint are summarized in Table II. ${ }^{1-4,10,11,13-19,} 21-45$ We conclude that cardiac manifestations do not differ according to the localization of the breakpoint. Persistent left superior vena cava seems to be consistent with breakpoints distal to q12, but the present case is different from them such that the breakpoint was p13.1. Besides, double outlet right ventricle is being reported for the first time in tetrasomy $9 p$ with a breakpoint at p13.1.

It is known that prognosis of tetrasomy $9 p$ is poor; almost half of patients died during the first year of life, and most of deaths occurred within the first 3 months of life. ${ }^{1}$ The present patient passed away at the 22nd day.
In conclusion, tetrasomy $9 \mathrm{p}$ presents with a recognizable constitution of facial dysmorphic features and congenital anomalies. Cardiac anomalies are frequent and diverse, also including double outlet right ventricle (severe form of tetralogy of Fallot type); however, no genotype-phenotype correlation seems to exist. Microarray analysis is useful in detecting the degree of mosaicism as well as the exact size of the copy number abnormality, thereby allowing a more precise establishment of genotypephenotype correlations in further patients.

\section{Acknowledgment}

The authors thank the patient's family and all the medical teams involved for their cooperation, and Dr. İlker Ertugrul (Department of Pediatric Cardiology Diseases, Hacettepe University Faculty of Medicine, Ankara, Turkey) for cardiologic evaluation.

\section{Ethical approval}

Ethics committee approval was received for this study from the Hacettepe University Non-Invasive Clinical Trials Ethics Committee (Approval number: GO 20/1151). Research was conducted ethically in accordance with the World Medical Association Declaration of Helsinki.

\section{Author contribution}

Conseption and design: MS, SO; supervision: HTC, POSK, GEU, SY; data collection and preccessing: MS, SO, GK, HTC, SY; analysis and interpretation: MS, SO, GK, GEU; literature review: MS, SO; writer: MS, SO, GK, HTC, POSK, GEU; critical review: POSK, GEU, SY.

\section{Conflict of interest}

The authors declare that there is no conflict of interest. 
Table II. Cardiac manifestations of tetrasomy 9p according to the breakpoint.

\begin{tabular}{|c|c|c|c|}
\hline Cardiac manifestations & $\begin{array}{c}\text { Number of reported patients } \\
\text {-Breakpoint p10 or more } \\
\text { proximal }\end{array}$ & $\begin{array}{c}\text { Number of reported patients } \\
\text {-Breakpoint q12 or more } \\
\text { distal }\end{array}$ & $\begin{array}{l}\text { Present patient } \\
\text {-Breakpoint p13.1 }\end{array}$ \\
\hline Atrial septal defect & 2 & - & + \\
\hline Patent foramen ovale & 2 & - & - \\
\hline Atrioventricular septal defect & - & 1 & - \\
\hline Ventricular septal defect & - & 7 & - \\
\hline Patent ductus arteriosus & 3 & 1 & - \\
\hline Truncus arteriosus & - & 1 & - \\
\hline $\begin{array}{l}\text { Persistent left superior vena } \\
\text { cava }\end{array}$ & - & 4 & + \\
\hline Juxtaductal aortic coarctation & 1 & - & - \\
\hline Overriding aorta & - & 1 & - \\
\hline Pulmonary hypertension & 1 & - & - \\
\hline Septal hypertrophy & - & 1 & - \\
\hline Biventricular hypertrophy & 1 & - & - \\
\hline $\begin{array}{l}\text { Asymmetry of the cardiac } \\
\text { ventricles }\end{array}$ & 1 & - & - \\
\hline Hypoplastic left ventricle & - & 2 & - \\
\hline Hypoplastic left atrium & - & 1 & - \\
\hline $\begin{array}{l}\text { Cardiac echogenic focus in } \\
\text { prenatal ultrasound }\end{array}$ & 1 & - & - \\
\hline $\begin{array}{l}\text { Infundibular stenosis of the } \\
\text { right ventricular outflow tract }\end{array}$ & - & 1 & - \\
\hline Bicuspit aortic valve & 1 & - & - \\
\hline Aortic stenosis & - & 1 & - \\
\hline Thick tricuspid valve & - & 1 & - \\
\hline $\begin{array}{l}\text { Double outlet right ventricle } \\
\text { (tetralogy of Fallot type) }\end{array}$ & - & - & + \\
\hline
\end{tabular}

\section{REFERENCES}

1. El Khattabi L, Jaillard S, Andrieux J, et al. Clinical and molecular delineation of Tetrasomy 9p syndrome: report of 12 new cases and literature review. Am J Med Genet A 2015; 167: 1252-1261. https://doi. org/10.1002/ajmg.a.36932

2. Pinto IP, Minasi LB, Steckelberg R, da Silva CC, da Cruz AD. Mosaic Tetrasomy of 9p24.3q21.11 postnatally identified in an infant born with multiple congenital malformations: a case report. BMC Pediatr 2018; 18: 298. https://doi.org/10.1186/ s12887-018-1275-8

3. McAuliffe F, Winsor EJ, Chitayat D. Tetrasomy 9p mosaicism associated with a normal phenotype. Fetal Diagn Ther 2005; 20: 219-222. https://doi. org/10.1159/000083909
4. Papoulidis I, Kontodiou M, Tzimina M, et al. Tetrasomy 9p mosaicism associated with a normal phenotype in two cases. Cytogenet Genome Res 2012; 136: 237-241. https://doi.org/10.1159/000337520

5. Verheij JB, Bouman $K$, van Lingen RA, et al. Tetrasomy $9 p$ due to an intrachromosomal triplication of 9p13-p22. Am J Med Genet 1999; 86: 168-173. https://doi.org/10.1002/(SICI)10968628(19990910)86:2<168::AID-AJMG16>3.0.CO;2-Q

6. Brock JAK, Dyack S, Ludman M, Dumas N, Gaudet $\mathrm{M}$, Morash B. Mosaic tetrasomy $5 \mathrm{p}$ resulting from an isochromosome $5 p$ marker chromosome: case report and review of literature. Am J Med Genet A 2012; 158: 406-411. https://doi.org/10.1002/ajmg.a.34272

7. Elbastawisy HI, Ghaly SW, Abualhasan SJ. A rare case of isochromosome 10: i (10p) and i (10q). Middle East Journal of Medical Genetics 2015; 4: 24-27. https://doi.org/10.1097/01.MXE.0000456628.99671.86 
8. Fryer AE, Ashworth M, Hawe J, Pilling D, Pauling $\mathrm{M}$, Maye U. Isochromosome 20p associated with multiple congenital abnormalities. Clin Dysmorphol 2005; 14: 49-50. https://doi.org/10.1097/00019605200501000-00012

9. Liehr T, Claussen U, Starke H. Small supernumerary marker chromosomes (sSMC) in humans. Cytogenet Genome Res 2004; 107: 55-67. https://doi. org/10.1159/000079572

10. Chen CP, Chang TY, Chern SR, et al. Prenatal diagnosis of low-level mosaic tetrasomy $9 \mathrm{p}$ by amniocentesis. Prenat Diagn 2007; 27: 383-385. https://doi.org/10.1002/pd.1678

11. Chen CP, Wang LK, Chern SR, et al. Mosaic tetrasomy $9 p$ at amniocentesis: prenatal diagnosis, molecular cytogenetic characterization, and literature review. Taiwan J Obstet Gynecol 2014; 53: 79-85. https://doi. org/10.1016/j.tjog.2013.12.002

12. Ghymers D, Hermann B, Distèche C, Frederic J. Tétrasomie partielle du chromosome 9, à l'état de mosaïque, chez un enfant porteur de malformations multiples. Humangenetik 1973; 20: 273-282. https:// doi.org/10.1007/BF00385740

13. Grass FS, Parke Jr JC, Kirkman HN, et al. Tetrasomy 9p: Tissue-limited idic (9p) in a child with mild manifestations and a normal CVS result. Report and review. Am J Med Genet 1993; 47: 812-816. https:// doi.org/10.1002/ajmg.1320470603

14. Wang H, Xie LS, Wang Y, Mei J. Prenatal diagnosis of mosaic tetrasomy $9 p$ in a fetus with isolated persistent left superior vena cava. Taiwan J Obstet Gynecol 2015; 54: 204-205. https://doi.org/10.1016/j. tjog.2014.12.005

15. McDowall A, Blunt S, Berry A, Fensom A. Prenatal diagnosis of a case of tetrasomy 9p. Prenat Diagn 1989; 9: 809-811. https://doi.org/10.1002/ pd.1970091110

16. Boxill M, Becher N, Sunde L, Thelle T. Choroid plexus hyperplasia and chromosome $9 \mathrm{p}$ gains. Am J Med Genet A 2018; 176: 1416-1422. https://doi. org/10.1002/ajmg.a.38697

17. Fremond ML, Gitiaux C, Bonnet D, et al. Mosaic tetrasomy 9p: a mendelian condition associated with pediatric-onset overlap myositis. Pediatrics 2015; 136: e544-e547. https://doi.org/10.1542/peds.20150724

18. Ions R, Narayanan M, Browning M, Gaillard EA, Stiefel G, Tang JW. Case presentation: persistent adenovirus B3 infections associated with bronchiolitis obliterans treated with cidofovir in a child with mosaic tetrasomy 9p. BMC Infect Dis 2018; 18: 529. https://doi.org/10.1186/s12879-0183441-x
19. Lazebnik N, Cohen L. Prenatal diagnosis and findings of tetrasomy 9p. J Obstet Gynaecol Res 2015; 41: 997-1002. https://doi.org/10.1111/jog.12706

20. Sifuentes-Dominguez L, Starokadomskyy P, Welch J, et al. Mosaic tetrasomy 9p associated with inflammatory bowel disease. J Crohns Colitis 2019; 13: 1474-1478. https://doi.org/10.1093/ecco-jcc/jjz079

21. Dhandha S, Hogge W, Surti U, McPherson E. Three cases of tetrasomy 9p. Am J Med Genet 2002; 113: 375-380. https://doi.org/10.1002/ajmg.b.10826

22. Nakamura-Pereira M, Cima LC, Llerena JC Jr, Guerra FA, Peixoto-Filho FM. Sonographic findings in a case of tetrasomy $9 \mathrm{p}$ associated with increased nuchal translucency and Dandy-Walker malformation. J Clin Ultrasound 2009; 37: 471-474. https://doi. org/10.1002/jcu.20612

23. Shehab MI, Mazen I, Bint S. Tissue-specific mosaicism for tetrasomy 9p uncovered by array CGH. Am J Med Genet A 2011; 155A: 2496-2500. https://doi.org/10.1002/ajmg.a.34176

24. di Vera E, Liberati M, Celentano $C$, et al. Rhombencephalosynapsis in a severely polymalformed fetus with non-mosaic tetrasomy 9p, in intracytoplasmic-sperm-injection pregnancy. J Assist Reprod Genet 2008; 25: 577-580. https:/doi. org/10.1007/s10815-008-9257-7

25. Ogino W, Takeshima Y, Nishiyama A, Yagi M, Oka N, Matsuo M. Mosaic tetrasomy 9p case with the phenotype mimicking Klinefelter syndrome and hyporesponse of gonadotropin-stimulated testosterone production. Kobe J Med Sci 2007; 53:143-150.

26. Tan $Y Q$, Chen XM, Hu L, Guan XY, Lu GX. Prenatal diagnosis of nonmosaic tetrasomy $9 p$ by microdissection and FISH: case report. Chin Med J (Engl) 2007; 120: 1281-1283. https://doi. org/10.1097/00029330-200707020-00016

27. Henriques-Coelho T, Oliva-Teles N, Fonseca-Silva ML, Tibboel D, Guimaraes H, Correia-Pinto J. Congenital diaphragmatic hernia in a patient with tetrasomy 9p. J Pediatr Surg 2005; 40: e29-e31. https://doi.org/10.1016/j.jpedsurg.2005.06.032

28. Deurloo KL, Cobben JM, Heins YM, de Ru M, Wijnaendts LC, van Vugt JM. Prenatal diagnosis of tetrasomy $9 \mathrm{p}$ in a 19-week-old fetus with DandyWalker malformation: a case report. Prenat Diagn 2004; 24: 796-798. https://doi.org/10.1002/pd.850

29. Hengstschlager M, Bettelheim D, Drahonsky R, Repa C, Deutinger J, Bernaschek G. Prenatal diagnosis of tetrasomy 9p with Dandy-Walker malformation. Prenat Diagn 2004; 24: 623-626. https://doi. org/10.1002/pd.933 
30. Tang W, Boyd BK, Hummel M, Wenger SL. Prenatal diagnosis of tetrasomy 9p. Am J Med Genet A 2004; 126A: 328. https://doi.org/10.1002/ajmg.a.20511

31. de Azevedo Moreira LM, Freitas LM, Gusmao FA, Riegel M. New case of non-mosaic tetrasomy $9 p$ in a severely polymalformed newborn girl. Birth Defects Res A Clin Mol Teratol 2003; 67: 985-988. https://doi. org/10.1002/bdra.10126

32. Lloveras E, Perez C, Sole F, et al. Two cases of tetrasomy $9 \mathrm{p}$ syndrome with tissue limited mosaicism. Am J Med Genet A 2004; 124A: 402-406. https://doi.org/10.1002/ajmg.a.20447

33. Cazorla Calleja MR, Verdu A, Felix V. Dandy-Walker malformation in an infant with tetrasomy 9p. Brain Dev 2003; 25: 220-223. https://doi.org/10.1016/S03877604(02)00211-5

34. Leichtman LG, Zackowski JL, Storto PD, Newlin A. Non-mosaic tetrasomy $9 \mathrm{p}$ in a liveborn infant with multiple congenital anomalies: Case report and comparison with trisomy 9p. Am J Med Genet 1996; 63: 434-437. https://doi.org/10.1002/(SICI)10968628(19960614)63:3<434::AID-AJMG4>3.0.CO;2-R

35. Rutten F, Scheres J, Hustinx TW, Haar Bt. A presumptive tetrasomy for the short arm of chromosome 9. Humangenetik 1974; 25: 163-170. https://doi.org/10.1007/BF00281423

36. Orye E, Verhaaren H, Van den Bogaert-Van Heesvelde AM. The 9p- deletion syndrome. Report of a patient with a $46, \mathrm{XX}, 9 \mathrm{P}$ - constitution due to a paternal $\mathrm{t}(9 \mathrm{p}-; 15+)$ translocation. Clin Genet 1975; 8: 349-357. https://doi.org/10.1111/j.1399-0004.1975. tb01513.x

37. Moedjono S, Crandall B, Sparkes R. Tetrasomy 9p: confirmation by enzyme analysis. J Med Genet 1980; 17: 227-230. https://doi.org/10.1136/jmg.17.3.227
38. Schaefer GB, Domek DB, Morgan MA, Muneer RS, Johnson SF. Tetrasomy of the short arm of chromosome 9: prenatal diagnosis and further delineation of the phenotype. Am J Med Genet 1991; 38: 612-615. https://doi.org/10.1002/ajmg.1320380422

39. Eggermann T, Rossier E, Theurer-Mainka U, et al. New case of mosaic tetrasomy $9 p$ with additional neurometabolic findings. Am J Med Genet 1998; 75: 530-533. https://doi.org/10.1002/(SICI)10968628(19980217)75:5<530::AID-AJMG14>3.0.CO;2-L

40. Tonk VS. Moving towards a syndrome: a review of 20 cases and a new case of non-mosaic tetrasomy 9p with long-term survival. Clin Genet 1997; 52: 23-29. https://doi.org/10.1111/j.1399-0004.1997.tb02510.x

41. Balestrazzi P, Croci G, Frassi C, Franchi F, Giovannelli G. Tetrasomy 9p confirmed by GALT. J Med Genet 1983; 20: 396-399. https://doi.org/10.1136/ jmg.20.5.396

42. Dutly F, Balmer D, Baumer A, Binkert F, Schinzel A. Isochromosomes 12p and 9p: parental origin and possible mechanisms of formation. Eur J Hum Genet 1998; 6: 140. https://doi.org/10.1038/sj.ejhg.5200168

43. Stumm M, Tönnies H, Mandon U, Götze A, Krebs $\mathrm{P}$, Wieacker P. Mosaic tetrasomy $9 \mathrm{p}$ in a girl with multiple congenital anomalies: cytogenetic and molecular-cytogenetic studies. Eur J Pediatr 1999; 158: 571-575. https://doi.org/10.1007/s004310051149

44. Wisniewski L, Politis G, Higgins J. Partial tetrasomy 9 in a liveborn infant. Clin Genet 1978; 14: 147-153. https://doi.org/10.1111/j.1399-0004.1978.tb02120.x

45. Calvieri F, TozziC, BenincoriC, etal. Partial tetrasomy 9 in an infant with clinical and radiological evidence of multiple joint dislocations. Eur J Pediatr 1988; 147: 645-648. https://doi.org/10.1007/BF00442483 